Western University

Scholarship@Western

$2-1-2012$

Evaluating bronchodilator effects in chronic obstructive pulmonary disease using diffusion-weighted hyperpolarized helium-3 magnetic resonance imaging

Miranda Kirby

Mohammadreza Heydarian

Andrew Wheatley

David G McCormack

Grace Parraga

Follow this and additional works at: https://ir.lib.uwo.ca/biophysicspub

Part of the Medical Biophysics Commons

Citation of this paper:

Kirby, Miranda; Heydarian, Mohammadreza; Wheatley, Andrew; McCormack, David G; and Parraga, Grace, "Evaluating bronchodilator effects in chronic obstructive pulmonary disease using diffusion-weighted hyperpolarized helium-3 magnetic resonance imaging" (2012). Medical Biophysics Publications. 115.

https://ir.lib.uwo.ca/biophysicspub/115 


\title{
Evaluating bronchodilator effects in chronic obstructive pulmonary disease using diffusion-weighted hyperpolarized helium-3 magnetic resonance imaging
}

\author{
Miranda Kirby, ${ }^{1,2}$ Mohammadreza Heydarian, ${ }^{2}$ Andrew Wheatley, ${ }^{2}$ David G. McCormack, ${ }^{3}$ \\ and Grace Parraga ${ }^{1,2,4}$ \\ ${ }^{1}$ Department of Medical Biophysics, The University of Western Ontario; ${ }^{2}$ Imaging Research Laboratories, Robarts Research \\ Institute; and ${ }^{3}$ Division of Respirology, Department of Medicine, and ${ }^{4}$ Graduate Program in Biomedical Engineering, \\ The University of Western Ontario, London, Canada
}

Submitted 18 October 2011; accepted in final form 1 December 2011

\begin{abstract}
Kirby M, Heydarian M, Wheatley A, McCormack DG, Parraga G. Evaluating bronchodilator effects in chronic obstructive pulmonary disease using diffusion-weighted hyperpolarized helium-3 magnetic resonance imaging. J Appl Physiol 112: 651-657, 2012. First published December 8, 2011; doi:10.1152/japplphysiol.01295.2011.—The objective of this study was to evaluate the regional effects of bronchodilator administration in chronic obstructive pulmonary disease (COPD) using hyperpolarized helium-3 ( $\left.{ }^{3} \mathrm{He}\right)$ MRI apparent diffusion coefficient (ADC). Ten COPD ex-smokers provided written, informed consent and underwent diffusion-weighted, hyperpolarized ${ }^{3} \mathrm{He}$ MRI, spirometry, and plethysmography before and $25 \pm 2$ min after bronchodilator administration. Pre- and postsalbutamol whole-lung (WL) ADC maps were generated and registered together to identify the lung regions containing the ${ }^{3} \mathrm{He}$ signal at both time points, and mean ADC within those regions of interest (ROI) was determined for a measurement of previously ventilated ROI ADC (ADC $\mathrm{P}_{\mathrm{P}}$. Lung ROI with ${ }^{3} \mathrm{He}$ signal at both time points was used as a binary mask on postsalbutamol WL ADC maps to obtain an ADC measurement for newly ventilated ROI $\left(\mathrm{ADC}_{\mathrm{N}}\right)$. Postsalbutamol, no significant differences were detected in $\mathrm{WL} \operatorname{ADC}(P=0.516)$. There were no significant differences between $\mathrm{ADC}_{\mathrm{N}}$ and $\mathrm{ADC}_{\mathrm{P}}$ postsalbutamol $(P=1.00)$, suggesting that the $\mathrm{ADC}_{\mathrm{N}}$ lung regions were not more emphysematous than the lung ROI participating in ventilation before bronchodilator administration. Postsalbutamol, a statistically significant decrease in $\operatorname{ADC}_{\mathrm{P}}(P=0.01)$ was detected, and there were significant differences between $\mathrm{ADC}_{\mathrm{P}}$ in the most anterior and most posterior image slices $(P=0.02)$, suggesting a reduction in regional gas trapping following bronchodilator administration. Regional evaluation of tissue microstructure using hyperpolarized ${ }^{3} \mathrm{He}$ MRI ADC provides insights into lung alterations that accompany improvements in regional ${ }^{3} \mathrm{He}$ gas distribution after bronchodilator administration.
\end{abstract}

apparent diffusion coefficients; chronic obstructive pulmonary disease

CHRONIC OBSTRUCTIVE PULMONARY DISEASE (COPD) is characterized by progressive expiratory flow limitation that develops as a result of the lung's inflammatory response to inhaled toxic gases and particles, primarily from tobacco smoke (37). Airflow limitation may be caused by a number of factors, such as lumen occlusion via mucus plugs (14); structural alteration of the airway wall, resulting in encroachment of the airway wall into the airway lumen $(15,24)$; and/or a loss of elastic recoil within the lung parenchyma due to emphysematous tissue destruction that leads to reduced tethering forces stabilizing the airways at forced expiration (36). The prolongation of the time

\footnotetext{
Address for reprint requests and other correspondence: G. Parraga, Imaging Research Laboratories, Robarts Research Institute, 100 Perth Dr., London, Canada N6A 5K8 (e-mail: gep@imaging.robarts.ca).
}

constants for lung emptying results in numerous physiological and functional consequences, including hyperinflation and gas trapping, as well as ventilation abnormalities that lead to many of the disabling symptoms associated with COPD, such as dyspnea and limitation of exercise capacity $(16,34)$.

Administration of short-acting $\beta$-agonist bronchodilators is first-line therapy in the symptomatic management of COPD (35), and this is thought to decrease airway smooth muscle tone, thereby improving lung emptying during expiration (28). Whereas improvements in airflow limitation and reductions in lung hyperinflation following bronchodilator administration have been shown previously $(2,29,30)$, there is still little understanding about the regional nature of the bronchodilator response in COPD. In this regard, pulmonary MRI using hyperpolarized helium-3 $\left({ }^{3} \mathrm{He}\right)$ provides high spatial and temporal resolution in in vivo images of ${ }^{3} \mathrm{He}$ gas distribution within the lung in COPD subjects $(3,4,8,17,19,22,23,25$, 38). In COPD ex-smokers, we previously observed significant improvements in the regional distribution of ${ }^{3} \mathrm{He}$ gas after bronchodilator administration (18); however, it was unclear whether these regional improvements were related to physiological or symptomatic improvements. The measurement of the ${ }^{3} \mathrm{He}$ apparent diffusion coefficient (ADC) has been demonstrated to be highly reproducible $(6,26,33)$ and is sensitive to changes in the lung microstructure and airspace size (38, 43, 44), correlating with spirometry (39), diffusing capacity of carbon monoxide (11), multislice computed tomography (CT) measurements of emphysema (5), as well as lung surface-area measurements (41). ${ }^{3} \mathrm{He}$ MRI ADC measurements are also age dependent (9) and reflect the Global Initiative for Chronic Obstructive Lung Disease (GOLD) classification of disease severity (8) and smoking history (11) and detect gas trapping within the dependent lung regions in COPD (7).

We hypothesized that the improvements in ${ }^{3} \mathrm{He}$ gas distribution, which we observed previously after bronchodilation in COPD, may be the direct source of symptomatic relief following therapy. To help test this hypothesis, here, we aimed to evaluate hyperpolarized ${ }^{3} \mathrm{He}$ MRI ADC as a surrogate of the extent of emphysematous tissue destruction within the newly ventilated regions of interest [ROI $\left(\mathrm{ADC}_{\mathrm{N}}\right)$; postbronchodilator] and to evaluate regional gas trapping following bronchodilator administration. We evaluated lung microstructural measurements using regional ${ }^{3} \mathrm{He}$ MRI ADC in COPD before and after bronchodilator administration (18), after developing image registration/segmentation methods for quantifying ADC in the lung regions' newly ventilated postbronchodilator. 


\section{MATERIALS AND METHODS}

Subjects. All subjects were enrolled in a ${ }^{3} \mathrm{He}$ MRI study of the acute effects of salbutamol administration (18), in which written, informed consent to the protocol, approved by the local research ethics board and Health Canada, was provided, and the study was compliant with the Personal Information Protection and Electronic Documents Act (Canada) and the Health Insurance Portability and Accountability Act (USA). COPD subjects were enrolled who were ex-smokers between the ages of 50 and 85 , with a clinical diagnosis of COPD, and were categorized according to the GOLD criteria (37) with a smoking history of at least 10 pack years. Subjects were required to withhold short-acting bronchodilators the morning of their study visit. Prebronchodilator MRI was performed immediately following pulmonary function tests, and postbronchodilator MRI was performed $25 \mathrm{~min}( \pm 2 \mathrm{~min}$ ) after administration of $400 \mu \mathrm{g}$ salbutamol, inhaled via a spacer device. Digital pulse oximetry was used to measure arterial oxygen saturation $\left(\mathrm{SaO}_{2}\right)$ during scanning sessions, and a hypoxic adverse event was defined as a decrease in $\mathrm{SaO}_{2}$ below $88 \%$ at any time during imaging. Study withdrawal was required when $\mathrm{SaO}_{2}$ decreased to $80 \%$ for $10 \mathrm{~s}$ or longer.

Pulmonary function tests. Spirometry was performed using an ndd EasyOne spirometer (ndd Medizintechnik AG, Zurich), reporting forced expiratory volume in $1 \mathrm{~s}\left(\mathrm{FEV}_{1}\right)$ and forced vital capacity (FVC), with a minimum of three acceptable spirometry maneuvers, with the best $\mathrm{FEV}_{1}$ and $\mathrm{FVC}$ selected for analysis, according to American Thoracic Society guidelines. Total lung capacity (TLC), inspiratory capacity (IC), functional residual capacity (FRC), and residual volume (RV) were measured using body plethysmography (Medgraphics, St. Paul, MN).

Image acquisition. MRI was performed on a whole-body 3.0 Tesla Excite 12.0 MRI system [General Electric Healthcare (GEHC), Waukesha, WI] with broadband imaging capability, as described previously (40). All helium imaging used a whole-body gradient set with maximum gradient amplitude of $1.94 \mathrm{G} / \mathrm{cm}$ and a single-channel rigid elliptical transmit/receive chest coil (Rapid Biomedical $\mathrm{GmbH}$, Germany). The basis frequency of the coil was $97.3 \mathrm{MHz}$, and excitation power was $3.2 \mathrm{~kW}$ using an AMT 3 T90 radiofrequency (RF) power amplifier (GEHC, Waukesha, WI). Subjects were positioned supine in the MR scanner, and $\mathrm{SaO}_{2}$ was used to monitor arterial blood oxygenation levels during all MRI maneuvers. For both ${ }^{1} \mathrm{H}$ and ${ }^{3} \mathrm{He}$ MRI, subjects were instructed by a pulmonary function technologist to inhale a gas mixture from a 1.0-liter Tedlar bag (Jensen Inert Products, Coral Springs, FL) from FRC, and image acquisition was performed under breath-hold conditions (a period of $8-15 \mathrm{~s})$.

Coronal proton $\left({ }^{1} \mathrm{H}\right)$ MRI was performed prior to hyperpolarized ${ }^{3} \mathrm{He}$ MRI with subjects scanned during breath-hold after inspiration of a 1.0-liter ${ }^{4} \mathrm{He} / \mathrm{N}_{2}$ gas mixture using the whole-body $\mathrm{RF}$ coil and ${ }^{1} \mathrm{H}$ fast-spoiled, gradient-recalled echo sequence [16 s total data acquisition, repetition time (TR)/echo time (TE)/flip angle $=4.7 \mathrm{~ms} / 1.2$ $\mathrm{ms} / 30^{\circ}$, field-of-view $(\mathrm{FOV})=40 \times 40 \mathrm{~cm}$, matrix $256 \times 128,14$ slices, $15 \mathrm{~mm}$ slice thickness, 0 gap], as described previously (12).

Prior to ${ }^{3} \mathrm{He}$ MRI, a polarizer system (Helispin, GEHC, Durham, $\mathrm{NC}$ ) was used to polarize ${ }^{3} \mathrm{He}$ gas to $30-40 \%$. As described previously (21), hyperpolarized ${ }^{3} \mathrm{He}$ MRI diffusion-weighted images were acquired in breath-hold after inspiration of a 1.0-liter ${ }^{3} \mathrm{He} / \mathrm{N}_{2}$ mixture ( $5 \mathrm{~mL} / \mathrm{kg}$ body wt) using a fast gradient-echo method with centric $\mathrm{k}$-space sampling. Two interleaved images were acquired (14 s total data acquisition, TR/TE/flip angle $=7.6 \mathrm{~ms} / 3.7 \mathrm{~ms} / 8^{\circ}, \mathrm{FOV}=40 \times$ $40 \mathrm{~cm}$, matrix $128 \times 128$, seven slices, $30 \mathrm{~mm}$ slice thickness), with and without additional diffusion sensitization [strength $(\mathrm{G})=1.94$ $\mathrm{G} / \mathrm{cm}$, rise and fall time $=0.5 \mathrm{~ms}$, gradient duration $=0.46 \mathrm{~ms}$, interval $\Delta=1.46 \mathrm{~ms}$, duration and strength $\left.(\mathrm{b})=1.6 \mathrm{~s} / \mathrm{cm}^{2}\right]$.

Image analysis. ${ }^{3} \mathrm{He}$ MRI ADC analysis was performed using MATLAB R2007b (MathWorks, Natick, MA). To ensure that ADC was generated for voxels corresponding to ventilated lung regions, k-means cluster algorithm (21), developed previously for ${ }^{3} \mathrm{He}$ MRI segmentation $(13,18,20)$, was applied to the nondiffusion-weighted images to obtain a binary mask for each slice. The resulting binary masks were applied to the corresponding nondiffusion-weighted images, and the ADC maps were generated on a voxel-by-voxel basis according to Eq. 1

$$
A D C=\frac{1}{b} \ln \left(\frac{\mathrm{S}_{0}}{\mathrm{~S}}\right)
$$

where $S_{0}$ is the segmented nondiffusion-weighted image, $S$ is the diffusion-weighted image, and $b=1.6 \mathrm{~s} / \mathrm{cm}^{2}$.

An overview of the ${ }^{3} \mathrm{He}$ MRI analysis methodology is provided in Fig. 1. To minimize the potential for differences in the levels of inspiration between pre- and postsalbutamol imaging, extensive coaching was performed among the breath-hold scans for all subjects. Pre- and postsalbutamol ADC maps were registered using landmarkbased image registration. Briefly, the center slice, defined as the slice that clearly showed the carina and primary bronchi, was identified in the nondiffusion-weighted images for each imaging time point and displayed side by side. A fiducial marker was identified on both the pre- and postsalbutamol ${ }^{3} \mathrm{He}$ images, based on the carina, and a translation operation was used to transform the postsalbutamol image for registration with the corresponding landmark in the presalbutamol image. The resultant transformation was then applied to the ${ }^{3} \mathrm{He}$ ADC maps for all slices. The trachea and visible major airways were removed semiautomatically using a ROI (function ROIPOLY in MATLAB), permitting ADC calculation within the lung parenchyma.

Whole-lung (WL) ADC values were determined for each slice and then averaged to obtain a single ADC for each subject. Following registration of the pre- and postsalbutamol ADC maps, the lung ROI with ${ }^{3} \mathrm{He}$ signal at both time points were identified as the intersection of the pre- and postsalbutamol maps; mean ADC within those ROI was generated for each slice and then averaged to obtain a previously ventilated $\mathrm{ADC}\left(\mathrm{ADC}_{\mathrm{P}}\right)$ for both presalbutamol and postsalbutamol conditions. Lung ROI with a ${ }^{3} \mathrm{He}$ signal at both time-points were used as a binary ventilation mask on the postsalbutamol ADC maps to calculate mean $\mathrm{ADC}$ in $\mathrm{ADC}_{\mathrm{N}}$. To ensure that $\mathrm{ADC}$ estimates were generated for the $\mathrm{ADC}_{\mathrm{N}}$ postsalbutamol and to minimize the contribution of patient movement or breath-hold mismatch between imaging time-points, we used a morphological closing algorithm on the postsalbutamol ADC maps (function imclose in MATLAB) with a disk-shaped structuring element, with radius $=1$. The resultant binary masks were applied to the ADC maps of the $\mathrm{ADC}_{\mathrm{N}}$ postsalbutamol, and mean $\mathrm{ADC}_{\mathrm{N}}$ was determined.

Statistical methods. All statistical analyses were performed using IBM SPSS Statistics 19.0 (IBM, Chicago, IL). Multivariate ANOVA and repeated measures ANOVA were performed for comparison of pre- and postsalbutamol pulmonary function measurements. Statistical comparisons of mean pre- and postsalbutamol WL ADC and $\mathrm{ADC}_{\mathrm{P}}$ measurements were performed using a two-way mixed-design repeated measures ANOVA with imaging time point (pre- and postsalbutamol) treated as the within-subject factor and subject treated as the between-subjects factor. Comparison between $\mathrm{ADC}_{\mathrm{P}}$ and $\mathrm{ADC}_{\mathrm{N}}$ postsalbutamol was also performed using a two-way mixed-design repeated measures ANOVA with ROI $\left(\mathrm{ADC}_{\mathrm{P}}\right.$ or $\mathrm{ADC}_{\mathrm{N}}$ postsalbuta$\mathrm{mol}$ ), treated as the within-subject factor and subject treated as the between-subjects factor. Anatomical differences in ADC within the regions of the lung ventilated at both time-points were quantified by determining the mean $\mathrm{ADC}$ in the most posterior slice and by calculating the absolute difference in ADC between the most anterior and the most posterior slice $(\triangle \mathrm{AP})$. Comparisons between mean ADC in the most posterior slice and $\Delta \mathrm{AP}$ pre- and postsalbutamol were determined using a two-tailed Wilcoxon signed-rank $t$-test. Spearman correlation coefficients were used to determine the relationship between $\mathrm{ADC}$ and pulmonary function measurements. In all statistical 

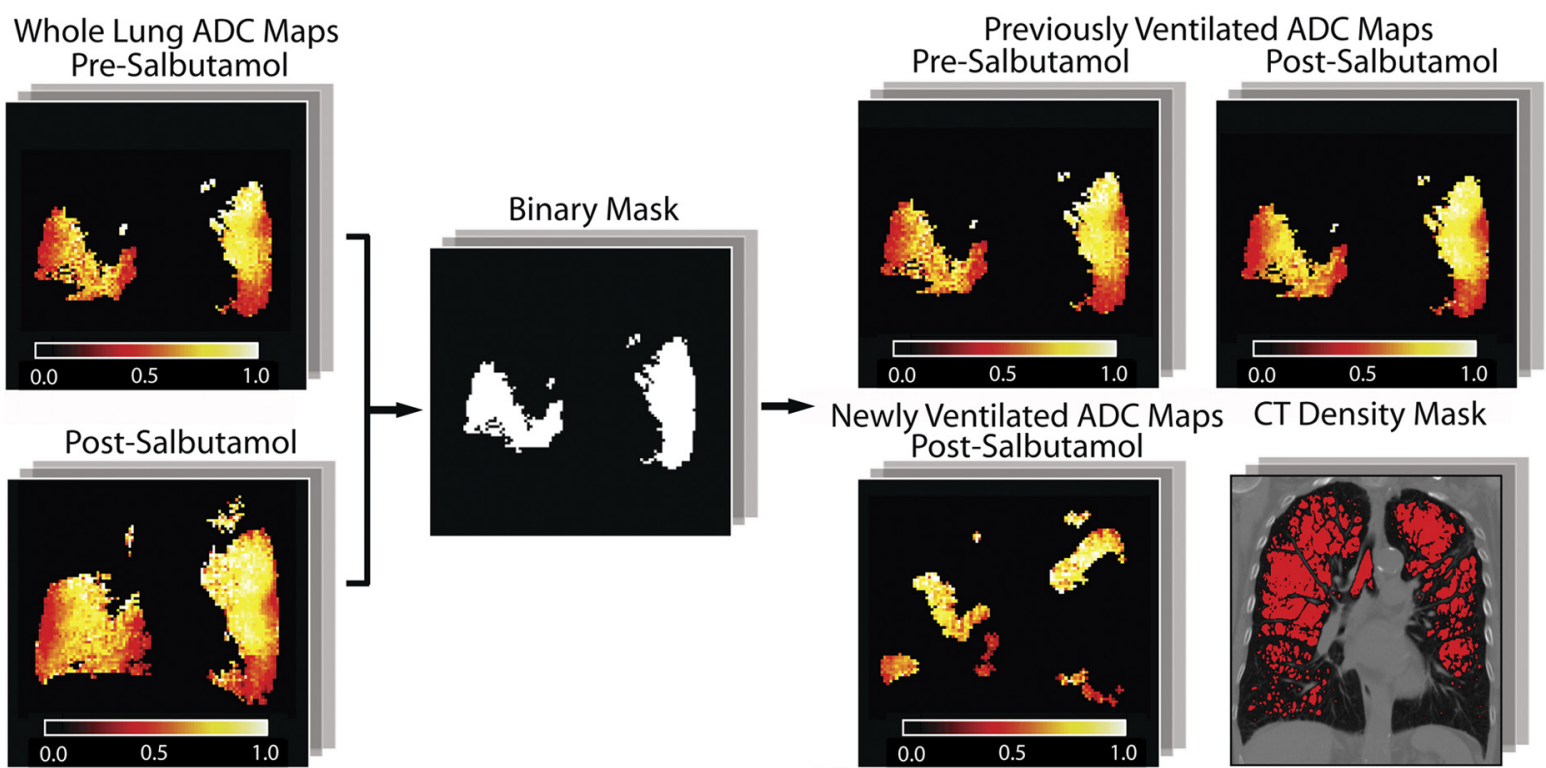

Newly Ventilated ADC Maps CT Density Mask
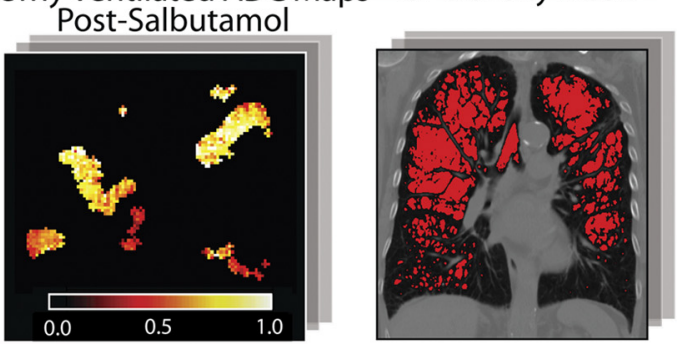

Fig. 1. Helium-3 ( $\left.{ }^{3} \mathrm{He}\right)$ MRI image analysis methodology. Subject is 74 yrs old female with Stage II chronic obstructive pulmonary disease [COPD; forced expiratory volume in $1 \mathrm{~s}\left(\mathrm{FEV}_{1}\right)=47 \%$ predicted $(47 \%$ pred $)$, forced vital capacity $(\mathrm{FVC})=92 \%$ pred, $\mathrm{FEV}_{1} / \mathrm{FVC}=39 \%$, diffusing capacity of carbon monoxide $(\mathrm{DLCO})=20 \%$ pred $].{ }^{3} \mathrm{He}$ apparent diffusion coefficient (ADC) maps pre- and postsalbutamol, binary ventilation mask of lung regions of interest (ROI) with ${ }^{3} \mathrm{He}$ signal at both time points following registration of pre- and postsalbutamol ADC maps, ${ }^{3} \mathrm{He}$ ADC maps for the previously ventilated (ADC $\mathrm{C}_{\mathrm{P}}$ ) lung ROI pre- and postsalbutamol, and ${ }^{3} \mathrm{He} \mathrm{ADC}$ maps for newly ventilated $\left(\mathrm{ADC}_{\mathrm{N}}\right)$ lung ROI postsalbutamol with the computed tomography $(\mathrm{CT})$ density masks to outline areas with attenuation values $<-950 \mathrm{HU}$. CT images were acquired 19 mo following pre- and postsalbutamol imaging.

analyses, results were considered significant when the probability of making a Type I error was $<5 \%(P<0.05)$.

\section{RESULTS}

All subjects completed both scanning sessions, and there were no serious or severe breath-hold-related or other adverse events reported, nor were there any other adverse events that required subjects to withdraw from the study. Table 1 shows study subject demographics and mean pulmonary function measurements ( $n=3$ Stage II, $n=6$ Stage III, and $n=1$ Stage IV) before and after salbutamol administration. Statistically significant postsalbutamol changes were observed for $\mathrm{FEV}_{1}$ $(P=0.007)$, TLC $(P=0.02)$, FRC $(P=0.02)$, and RV $(P=$ $0.02)$.

Figure 2 shows representative ${ }^{3} \mathrm{He}$ ADC maps pre- and postsalbutamol for a single subject and identifies visually obvious alterations in gas distribution. Figure $3 A$ shows mean pre- and postsalbutamol ${ }^{3} \mathrm{He}$ MRI ADC measurements for all

Table 1. Subject demographics

\begin{tabular}{lccc}
\hline \hline Parameter & $\begin{array}{c}\text { Presalbutamol }( \pm \text { SD }) \\
\text { [range] }(n=10)\end{array}$ & $\begin{array}{c}\text { Postsalbutamol }( \pm \text { SD }) \\
\text { [range] }(n=10)\end{array}$ & $\begin{array}{c}\text { Significance of } \\
\text { Difference }(P)^{*}\end{array}$ \\
\hline Age yrs & \multicolumn{2}{c}{$70(6)[61-77]$} & - \\
Male sex & \multicolumn{2}{c}{4} & - \\
BMI kg/m & \multicolumn{2}{c}{$25(4)[18-30]$} & - \\
FEV 1 liter & $1.11(0.42)[0.63-2.06]$ & $1.23(0.49)[0.67-2.30]$ & 0.007 \\
FVC liter & $2.67(0.71)[1.52-4.06]$ & $2.80(0.86)[1.76-4.41]$ & 0.20 \\
FEV $/$ FVC & $0.41(0.09)[0.27-0.53]$ & $0.45(0.12)[0.32-0.70]$ & 0.08 \\
TLC liter & $6.68(1.21)[4.82-8.19]$ & $6.20(1.12)[4.71-7.74]$ & 0.02 \\
IC liter & $2.10(0.49)[1.39-3.09]$ & $1.99(0.60)[1.09-3.06]$ & 0.23 \\
FRC liter & $4.56(1.11)[3.14-5.97]$ & $4.21(1.04)[2.67-5.81]$ & 0.02 \\
RV liter & $3.81(0.89)[2.63-5.25]$ & $3.31(0.75)[2.16-4.36]$ & 0.02 \\
\hline
\end{tabular}

BMI, body mass index; $\mathrm{FEV}_{1}$, forced expiratory volume in $1 \mathrm{~s} ; \mathrm{FVC}$, forced vital capacity; TLC, total lung capacity; IC, inspiratory capacity; FRC, functional residual capacity; RV, residual volume. *Repeated measures ANOVA. subjects. There was no significant difference detected for WL ADC postsalbutamol $(P=0.516)$. As shown in Table 2 , no significant correlations were detected between the change in WL ADC postsalbutamol and the change in pulmonary function measurements. However, there was a significant correlation between presalbutamol WL ADC and the change in IC (r $=-0.68, P=0.03$ ).

Figure 4 shows two representative COPD subjects: the WL pre- and postsalbutamol ADC maps and the maps postsalbutamol. There was no statistically significant difference between $\mathrm{ADC}_{\mathrm{N}}$ and $\mathrm{ADC}_{\mathrm{P}}$ postsalbutamol $\left(\mathrm{ADC}_{P}=0.506 \pm 0.072\right.$ $\left.\mathrm{cm}^{2} / \mathrm{s}, \mathrm{ADC}_{\mathrm{N}}=0.504 \pm 0.082 \mathrm{~cm}^{2} / \mathrm{s}, P=1.00\right)$, nor were there any significant interactions between the $\mathrm{ADC}_{\mathrm{N}}$ and ADC $_{\mathrm{p}}$ postsalbutamol $(P=0.18)$, indicating no significant change in $\mathrm{ADC}$ within the $\mathrm{ADC}_{\mathrm{N}}$ lung areas following administration of salbutamol.

For $\mathrm{ADC}_{\mathrm{P}}$ measurements, there was a statistically significant decrease detected postsalbutamol $(P=0.013$; Fig. $3 A)$. As shown in Fig. $3 B$, the mean ADC in the most posterior slice was significantly lower postsalbutamol $(P=0.049)$. In addition, $\triangle \mathrm{AP}$ was significantly higher postsalbutamol $(P=$ 0.020 ), indicating that there was a difference in the mean ADC in the AP direction following bronchodilator therapy (Fig. 3C). As shown in Table 2 and Fig. 5, Spearman correlation coefficients indicate that the postsalbutamol change in $\mathrm{ADC}_{\mathrm{P}}$ was significantly correlated with the change in TLC $(\mathrm{r}=0.782$, $P=0.011)$, FRC $(\mathrm{r}=0.806, P=0.007)$, and RV $(\mathrm{r}=0.733$, $P=0.020)$.

\section{DISCUSSION}

We previously evaluated COPD ex-smokers using hyperpolarized ${ }^{3} \mathrm{He}$ MRI before and after bronchodilator administration and provided evidence of significant and visually obvious regional improvements in ${ }^{3} \mathrm{He}$ gas distribution following bron- 


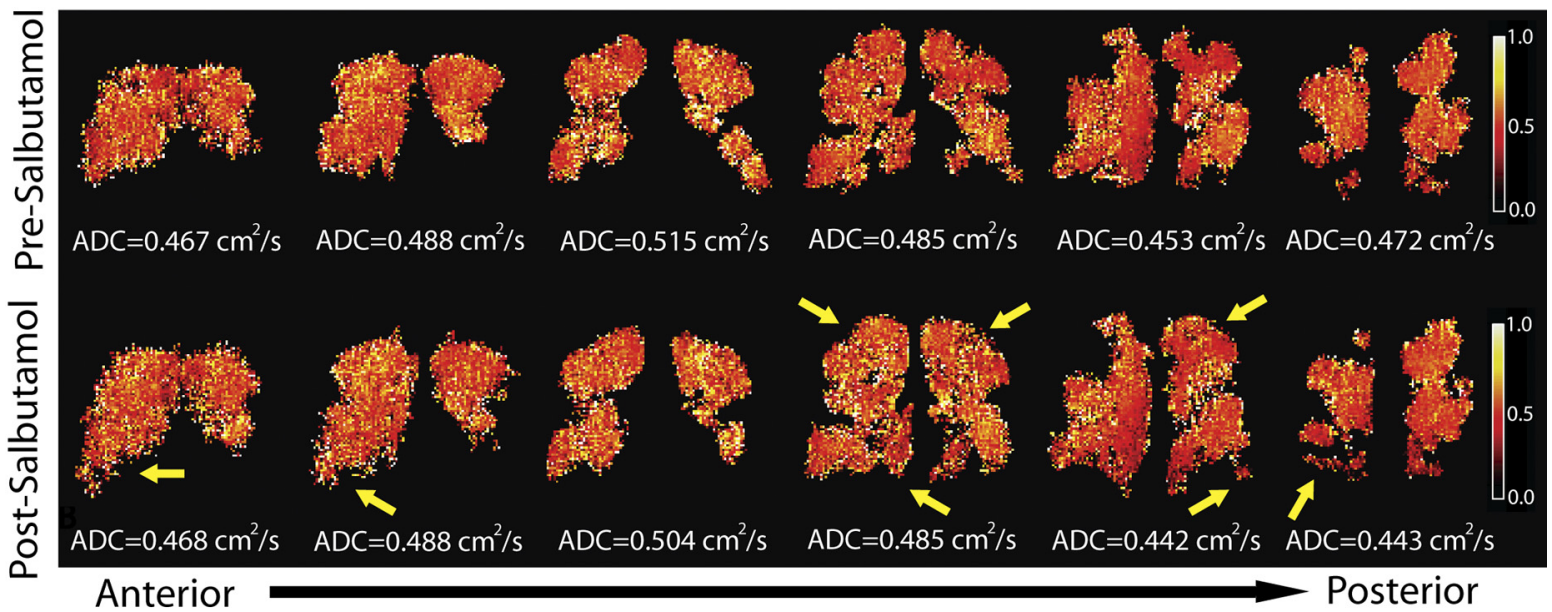

Fig. 2. ${ }^{3} \mathrm{He}$ whole-lung (WL) ADC presalbutamol and postsalbutamol. Subject is a 64-yr-old male with Stage III COPD [presalbutamol: FEV $1=38 \%$ pred, $\mathrm{FVC}=73 \%_{\text {pred }}$, total lung capacity $(\mathrm{TLC})=115 \%_{\text {pred }}$, functional residual capacity $(\mathrm{FRC})=147 \%_{\text {pred }}$, residual volume $(\mathrm{RV})=179 \%_{\text {pred }}, \mathrm{DLCO}=41 \%_{\text {pred }}$; postsalbutamol: $\mathrm{FEV}_{1}=43 \%_{\text {pred }}, \mathrm{FVC}=84 \%_{\text {pred }}$, TLC $=110 \%_{\text {pred, }}$ FRC $=133 \%_{\text {pred }}, \mathrm{RV}=170 \%_{\text {pred }}$. Pre- and postsalbutamol WL ADC maps with the corresponding mean ADC measurement shown below for each image slice.

chodilator therapy (18). Here, we extend these previous findings and explore the relationship of regional hyperpolarized ${ }^{3} \mathrm{He}$ ADC measurements in the pre- and postbronchodilator lung ROI. We aimed to determine whether the $\mathrm{ADC}_{\mathrm{N}}$ regions were different than lung ROI participating in ventilation before bronchodilation, and based on previous histological findings (41), we used the ${ }^{3} \mathrm{He}$ MRI ADC as a surrogate measurement of tissue microstructure. We made a number of observations and report the following: 1) mean WL ADC did not change postsalbutamol, 2) mean $\mathrm{ADC}$ in $\mathrm{ADC}_{\mathrm{N}}$ lung regions postsalbutamol was not different than mean $\left.\mathrm{ADC}_{\mathrm{P}}, 3\right)$ mean $\mathrm{ADC}$ in $\mathrm{ADC}_{\mathrm{P}}$ lung regions was significantly different (improved) postsalbutamol, and 4) ADC AP gradients significantly improved postsalbutamol.

\begin{tabular}{|c|c|c|c|c|}
\hline \multirow[t]{3}{*}{$\mathbf{A}$} & & $\begin{array}{c}\text { Pre-Salbutamol } \\
(n=10)\end{array}$ & $\begin{array}{c}\text { Post-Salbutamol } \\
(n=10)\end{array}$ & $\begin{array}{l}\text { Significance of } \\
\text { Difference }(p)\end{array}$ \\
\hline & WL ADC $\mathrm{cm}^{2} / \mathrm{s}( \pm \mathrm{SD})$ & $0.513(0.069)$ & $0.510(0.072)$ & 0.516 \\
\hline & \multirow{3}{*}{ WLADC $\mathrm{Cm}^{2} / \mathrm{s}( \pm \mathrm{SD})$} & $0.512(0.071)$ & $0.506(0.072)$ & $0.013^{*}$ \\
\hline \multirow{2}{*}{$\begin{array}{l}\text { Anterior } \\
\text { Posterior }\end{array}$} & & $0.501(0.091)$ & $0.504(0.091)$ & 0.922 \\
\hline & & $0.503(0.086)$ & $0.484(0.091)$ & $0.049^{*}$ \\
\hline & $\mathrm{AP} \mathrm{cm}^{2} / \mathrm{s}( \pm \mathrm{SD})$ & $0.002(0.123)$ & $0.020(0.123)$ & $0.020^{*}$ \\
\hline
\end{tabular}
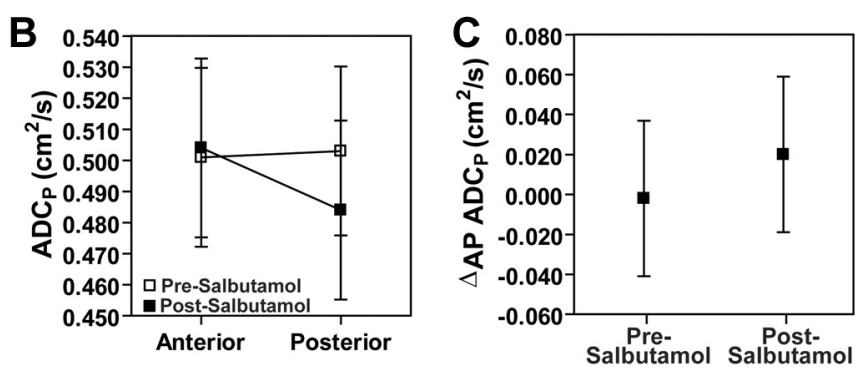

Fig. 3. Regional ${ }^{3} \mathrm{He}$ MRI ADC. Mean WL ADC measurements, mean WL $\mathrm{ADC}$ for the $\mathrm{ADC}_{\mathrm{P}}$ lung ROI, mean $\mathrm{ADP}_{\mathrm{P}}$ for the most anterior and posterior slices, and the absolute change in $\mathrm{ADC}_{\mathrm{P}}$ for the most anterior to the most posterior slice $(\triangle \mathrm{AP})$ pre- and postsalbutamol for all subjects $(A)$. Mean $\mathrm{ADC}_{\mathrm{P}}$ pre- and postsalbutamol for the most anterior and most posterior slices. Error bars are the $\mathrm{SE}(B)$. Mean $\triangle \mathrm{AP}$ for $\mathrm{ADC}_{\mathrm{P}}$ pre- and postsalbutamol. Error bars are the SE $(C)$.
First, we observed no significant change in WL ADC measurements following salbutamol administration, and this finding suggests that the alveolar structures that are probed by the ${ }^{3} \mathrm{He}$ gas postsalbutamol are not more emphysematous than the other lung ROI probed by the ${ }^{3} \mathrm{He}$ gas presalbutamol. In other words, this finding indicates that the bronchodilator was delivered primarily to the more normal lung regions. However, the ${ }^{3} \mathrm{He}$ ADC has been previously demonstrated to be sensitive to gas trapping in the dependent lung regions (7), which may lead to a reduction in the ADC measurement postbronchodilator. Because we observed no change in WL ADC postsalbutamol, we developed methods to determine regional ADC as a way to tease apart the potential combinations of reduced hyperinflation and gas redistribution to lung ROI with greater emphysematous destruction.

We applied these image processing methods and postsalbutamol, observed no significant difference between mean ADC in the $\mathrm{ADC}_{\mathrm{N}}$ and mean $\mathrm{ADC}$ in the $\mathrm{ADC}_{\mathrm{P}}$ lung, indicating that the lung ROI that participated in gas distribution following administration of salbutamol were not more emphysematous than lung ROI participating in gas distribution before salbutamol administration. These findings must be interpreted with an understanding of the limitations of the relatively large voxel size $(3.2 \mathrm{~mm} \times 3.2 \mathrm{~mm} \times 30 \mathrm{~mm})$ in this analysis and these images reflect the contributions of $\sim 70,000$ alveoli, estimated based on the mean size of a single, normal alveolus to be $4.2 \times 10^{-6} \mathrm{~cm}^{3}$, as described previously (32). Additionally,

Table 2. Correlation between the postsalbutamol change in $A D C$ and the change in pulmonary function measurements

\begin{tabular}{lcc}
\hline \hline \multirow{2}{*}{ Parameter } & \multicolumn{2}{c}{ Spearman Correlation Coefficients $(\mathrm{r})$} \\
\cline { 2 - 3 } & WL ADC $\left(\mathrm{cm}^{2} / \mathrm{s}\right)$ & WL ADC $\left(\mathrm{cm}^{2} / \mathrm{s}\right)$ \\
\hline TLC liter & $0.515(0.133)$ & $0.782(0.011)$ \\
IC liter & $0.139(0.707)$ & $0.285(0.427)$ \\
FRC liter & $0.636(0.054)$ & $0.806(0.007)$ \\
RV liter & $0.479(0.166)$ & $0.733(0.020)$ \\
\hline
\end{tabular}

$\mathrm{ADC}$, apparent diffusion coefficient; $\mathrm{WL}$, whole lung; $\mathrm{ADC}_{\mathrm{P}}$, previously ventilated regions of interest $\mathrm{ADC}$. 


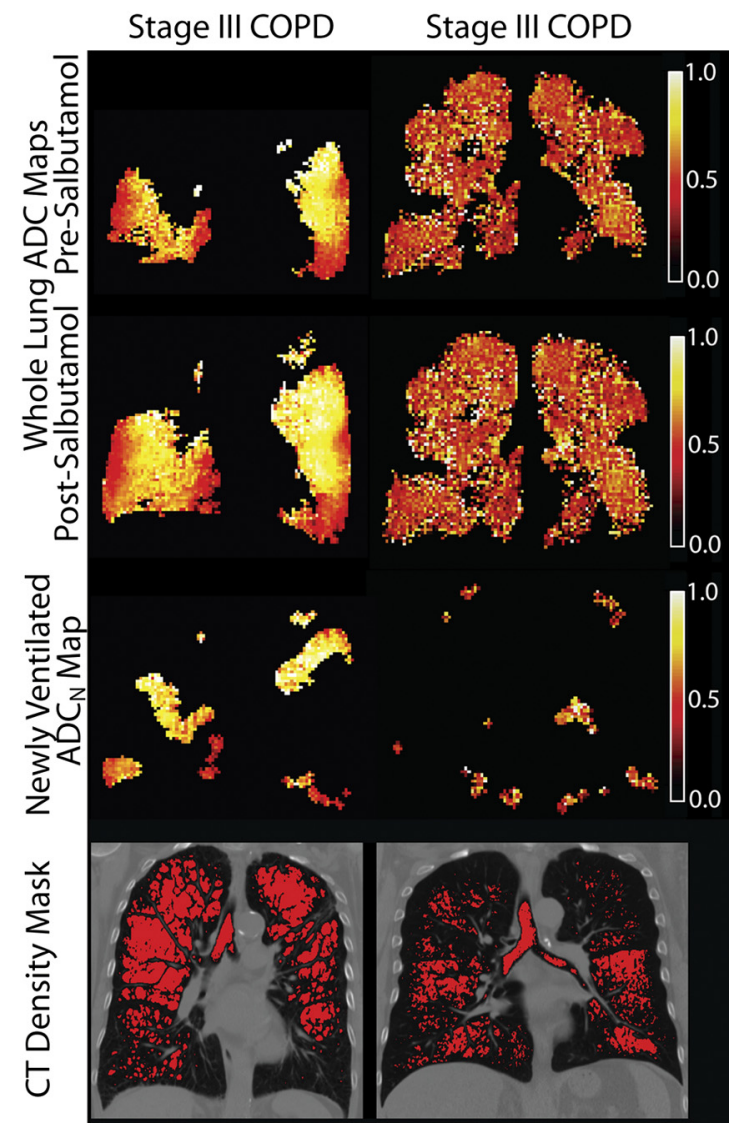

Fig. 4. Regional ${ }^{3} \mathrm{He}$ MRI ADC. WL center slice ${ }^{3} \mathrm{He}$ ADC maps pre- and postsalbutamol, ${ }^{3} \mathrm{He} \mathrm{ADC}$ maps for $\mathrm{ADC}_{\mathrm{N}}$ lung ROI postsalbutamol, and $\mathrm{CT}$ density masks to outline areas with attenuation values $<-950 \mathrm{HU}$ for a 74-yr-old female and a 64-yr-old male, both with Stage III COPD. CT images were acquired 15 mo following pre- and postsalbutamol imaging for the 74-yr-old subject and 28 mo following pre- and postsalbutamol imaging for the 64-yr-old subject.

the contribution of subject motion between imaging time points and the volume of gas within the lungs during the breath-hold imaging may have contributed to measurement uncertainty. Nevertheless, we have previously evaluated the ADC measurement within $1 \mathrm{wk}$ with no treatment (scan, 7-day rescan) (22) and determined that the estimated standard uncertainty (SD) of both the WL ADC and the center slice ROI ADC measurement in Stage II and Stage III COPD subjects was $0.001 \mathrm{~cm}^{2} / \mathrm{s}$, indicating that the ADC measurement in subjects with moderate-to-severe disease was remarkably reproducible. A previous study evaluating asthma subjects using ${ }^{3} \mathrm{He}$ MRI and multidetector CT demonstrated that there was a regional association between ${ }^{3} \mathrm{He}$ MRI ventilation abnormalities and CT measurements of gas trapping (10). Although it is plausible in the current study that emphysematous tissue destruction may have reduced the tethering of the airways at forced expiration (36), resulting in trapped gas and ventilation defects in severe COPD subjects, our findings suggest that defect regions that become ventilated in response to bronchodilators do not reflect more severe emphysema. Moreover, these results indicate that the bronchodilator acted on the obstructed small airways directly, allowing improvements in gas trapping and regional hyperinflation, and not on airways obstructed due to surrounding emphysema. As shown in Fig. 3, both emphysematous and healthy regions of the lung participated in gas distribution postsalbutamol. We must acknowledge that the very small number of newly ventilated voxels in the postsalbutamol images may lead to biased ADC values due to a low signal-tonoise ratio (SNR) (31), although this would have generated a bias toward higher ADC, and this was not observed in the current study. To minimize the potential for bias, we used a morphological closing algorithm to remove the contribution of small, isolated voxels to the mean ADC value, and a SNR threshold $>15$ for ADC generation was used as described previously (31).

We also observed a statistically significant reduction (improvement) in mean $\mathrm{ADC}_{\mathrm{P}}$ postsalbutamol. This small but significant improvement may be explained by both a reduction in the physical size of the airspaces due to the increased distribution of the ${ }^{3} \mathrm{He}$ gas (thereby effectively diluting the 1-liter dose) and bronchodilator-induced reduction in lung hyperinflation. To determine whether the significant change in $\mathrm{ADC}_{\mathrm{P}}$ was related to a reduction in lung hyperinflation, we compared the anatomical distribution of ADC values pre- and postsalbutamol. As described previously (7), airspaces are less compressible in COPD compared with healthy subjects in the dependent lung, likely because of gas trapping. We detected a statistically significant increase in $\triangle \mathrm{AP}$ and decreased mean $\mathrm{ADC}_{\mathrm{P}}$ in the most posterior slice postsalbutamol, suggesting that bronchodilator administration improved the expiratory time constants, which in turn, allowed the dependent lung regions to empty more completely. Moreover, as demonstrated
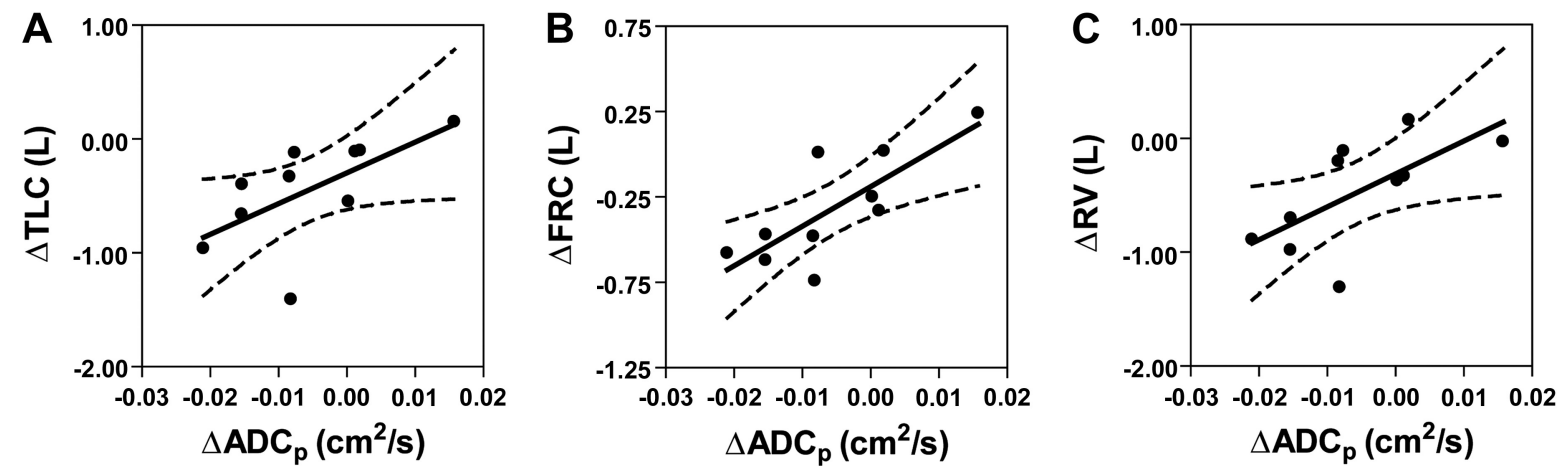

Fig. 5. Correlations between the postsalbutamol change $(\Delta)$ in ${ }^{3} \mathrm{He} \mathrm{ADC}_{\mathrm{P}}$ and pulmonary function measurements. $\Delta \mathrm{ADC}$ was correlated significantly with $\Delta \mathrm{TLC}$ $\left(\mathrm{r}=0.782, P=0.011 ; \mathrm{r}^{2}=0.387, P=0.055 ; \mathrm{y}=26.99 \times-0.30 ; A\right) ; \Delta$ FRC $\left(\mathrm{r}=0.806, P=0.007 ; \mathrm{r}^{2}=0.604, P=0.008 ; \mathrm{y}=23.13 \times-0.19 ; B\right) ;$ and $\Delta \mathrm{RV}\left(\mathrm{r}=0.733, P=0.020 ; \mathrm{r}^{2}=0.379, P=0.039 ; \mathrm{y}=28.91 \times-0.31 ; C\right)$. Dotted lines represent the $95 \%$ confidence intervals for the regressions. L, liter. 
in our previous study (18), there was no bias for any measurable changes in the distribution of ${ }^{3} \mathrm{He}$ gas postsalbutamol with respect to image slice, indicating that the reduction in mean $\mathrm{ADC}_{\mathrm{P}}$ within the dependent lung regions was not due to increased gas distribution in these regions. The significant correlation detected between the change in $\mathrm{ADC}_{\mathrm{P}}$ and changes in TLC, FRC, and RV postsalbutamol lends support to the hypothesis that the reduction in $\mathrm{ADC}_{\mathrm{P}}$ postsalbutamol was related to a reduction in gas trapping.

We recognize that this work was limited by the small number of subjects and the fact that the analysis was restricted mainly to subjects with moderate-to-severe COPD. Therefore, caution should be exercised in extrapolating these results to the general COPD population and more specifically, to patients with mild and very severe disease. An important limitation of ${ }^{3} \mathrm{He}$ MRI is that large regions of the lung are not ventilated or are poorly ventilated, preventing calculation of the ADC within these regions, and this may be due to small airway occlusion, mucous plugs, airway wall thickening and inflammation, severe emphysema, or bullous disease. Another limitation is the lack of a true reference standard for the measurement of treatment effects in COPD, such as dyspnea scores and measurements of exercise tolerance for direct comparison with ${ }^{3} \mathrm{He}$ MRI measurements to evaluate the clinical meaning of the imaging changes. In other words, whether the changes in ADC measures postsalbutamol are related to clinical, or symptomatic improvement remains to be established in a larger study. The lack of validation by an imaging reference method, such as CT or proton MRI with ultrashort TEs (UTE), is also a limitation of this work. Clearly, the direct comparison of functional and structural ${ }^{3} \mathrm{He}$ MRI, proton UTE MRI, CT, and symptomatic measurements will allow for a better understanding of the improvements in ${ }^{3} \mathrm{He}$ gas distribution observed after bronchodilator administration. It must also be noted that ${ }^{3} \mathrm{He}$ MRI ADC provides structural information, not only at the scale of the alveoli, probing emphysematous tissue destruction, but also at the scale of the alveolar ducts and the respiratory and terminal bronchioles (43); thus restriction to diffusion will differ in each of these structures, and alveoli diffusion will be more restricted than diffusion in the bronchioles. An important point related to this is the issue of collateral ventilation. In patients with emphysema, there is substantial collateral ventilatory pathways (27), including the pores of Kohn, canals of Lambert, and interbroncial communications of Martin. Although with the very short diffusion times used in this study, where the atoms are likely to be confined to the alveoli and acinar structures, measurements of ${ }^{3} \mathrm{He}$ diffusion over longer times and distances are likely sensitive to collateral ventilation paths $(1,42)$, which are significant in patients with emphysema. A better understanding of collateral ventilation and collateral pathways is required, and noninvasive imaging measurements, such as ${ }^{3} \mathrm{He}$ MRI ADC, may be useful for treatment planning, such as bronchoscopic airway bypass, and evaluating treatment effects. It is also important to note that study subjects were provided training and instruction for inspiration breathhold scanning, and they performed practice breath-holds and received coaching during breath-hold MRI. It is clear for all imaging studies that standardization is required for reproducible and comparable breath-hold volumes, and this is critically important for acute and chronic therapy repeated studies. Another important consideration is the limited ${ }^{3} \mathrm{He}$ MRI access and the high cost of ${ }^{3} \mathrm{He}$ gas that has, thus far, restricted translation of this functional imaging method to specialized MR physics centers. It is important to note the development of hyperpolarized ${ }^{129} \mathrm{Xe}$ MRI, a less expensive and more readily available approach and a promising alternative with which these reported findings can be tested directly.

In summary, this study demonstrated that ${ }^{3} \mathrm{He}$ MRI provides a noninvasive approach for the evaluation of regional structurefunction measurements after bronchodilator administration in COPD subjects. Lung microstructure in ROI that participate in gas distribution only after bronchodilator administration was not more emphysematous than ROI participating in gas distribution before bronchodilator use. We also demonstrated that regional ADCs reflect significant changes in the AP gradient following bronchodilator therapy, and this is possibly related to a reduction in regional gas trapping. The regional evaluation of hyperpolarized ${ }^{3} \mathrm{He}$ MRI ADC provides insights into regional lung microstructure for lung ROI that participate in ${ }^{3} \mathrm{He}$ gas distribution after bronchodilator administration.

\section{ACKNOWLEDGMENTS}

We thank S. McKay and S. Halko for clinical coordination and clinical database management and T. Szekeres for MRI of research volunteers.

\section{GRANTS}

M. Kirby gratefully acknowledges scholarship support from the Natural Sciences and Engineering Research Council (NSERC) of Canada and the Schulich Graduate Scholarship (SGS) provided by The University of Western Ontario (London, Canada). G. Parraga gratefully acknowledges salary support from a Canadian Institutes of Health Research (CIHR) New Investigator Award. Ongoing research funding from CIHR Operating Grants MOP \#97748 and MOP \#106437 and Team Grant CIF \#97687 is also gratefully acknowledged.

\section{DISCLOSURES}

We pay $\$ 100,000$ annually for the use of an on-site, hyperpolarized ${ }^{3} \mathrm{He}$ gas polarizer (Helispin, GEHC, Durham, NC).

\section{AUTHOR CONTRIBUTIONS}

M.K., D.G.M., and G.P. conception and design of research; M.K., A.W., and G.P. performed experiements; M.K., M.H., and G.P. analyzed data; M.K., A.W., D.G.M., and G.P. interpreted results of experiments; M.K. and G.P. prepared figures; M.K. and G.P. drafted manuscript; M.K., M.H., A.W., D.G.M., and G.P. edited and revised manuscript; and M.K., M.H., A.W., D.G.M., and G.P. approved final version of manuscript.

\section{REFERENCES}

1. Bartel SE, Haywood SE, Woods JC, Chang YV, Menard C, Yablonskiy DA, Gierada DS, Conradi MS. Role of collateral paths in longrange diffusion in lungs. J Appl Physiol 104: 1495-1503, 2008.

2. Belman MJ, Botnick WC, Shin JW. Inhaled bronchodilators reduce dynamic hyperinflation during exercise in patients with chronic obstructive pulmonary disease. Am J Respir Crit Care Med 153: 967-975, 1996.

3. Choy S, Wheatley A, McCormack DG, Parraga G. Hyperpolarized (3)He magnetic resonance imaging derived pulmonary pressure-volume curves. J Appl Physiol 109: 574-585, 2010.

4. de Lange EE, Mugler JP, III, Brookeman JR, Knight-Scott J, Truwit JD, Teates CD, Daniel TM, Bogorad PL, Cates GD. Lung air spaces: MR imaging evaluation with hyperpolarized 3He gas. Radiology 210: 851-857, 1999.

5. Diaz S, Casselbrant I, Piitulainen E, Magnusson P, Peterson B, Wollmer P, Leander P, Ekberg O, Akeson P. Validity of apparent diffusion coefficient hyperpolarized 3He-MRI using MSCT and pulmonary function tests as references. Eur J Radiol 71: 257-263, 2009.

6. Diaz S, Casselbrant I, Piitulainen E, Pettersson G, Magnusson P, Peterson B, Wollmer P, Leander P, Ekberg O, Akeson P. Hyperpolarized $3 \mathrm{He}$ apparent diffusion coefficient MRI of the lung: reproducibility 
and volume dependency in healthy volunteers and patients with emphysema. J Magn Reson Imaging 27: 763-770, 2008.

7. Evans A, McCormack D, Ouriadov A, Etemad-Rezai R, Santyr G, Parraga G. Anatomical distribution of (3)He apparent diffusion coefficients in severe chronic obstructive pulmonary disease. J Magn Reson Imaging 26: 1537-1547, 2007.

8. Evans A, McCormack DG, Santyr G, Parraga G. Mapping and quantifying hyperpolarized $3 \mathrm{He}$ magnetic resonance imaging apparent diffusion coefficient gradients. J Appl Physiol 105: 693-699, 2008.

9. Fain SB, Altes TA, Panth SR, Evans MD, Waters B, Mugler JP, III, Korosec FR, Grist TM, Silverman M, Salerno M, Owers-Bradley J. Detection of age-dependent changes in healthy adult lungs with diffusionweighted 3He MRI. Acad Radiol 12: 1385-1393, 2005.

10. Fain SB, Gonzalez-Fernandez G, Peterson ET, Evans MD, Sorkness RL, Jarjour NN, Busse WW, Kuhlman JE. Evaluation of structurefunction relationships in asthma using multidetector CT and hyperpolarized He-3 MRI. Acad Radiol 15: 753-762, 2008.

11. Fain SB, Panth SR, Evans MD, Wentland AL, Holmes JH, Korosec FR, O'Brien MJ, Fountaine H, Grist TM. Early emphysematous changes in asymptomatic smokers: detection with $3 \mathrm{He}$ MR imaging. Radiology 239: 875-883, 2006.

12. Heydarian M, Kirby M, Choy S, Wheatley A, Costella S, EtemadRezai R, McCormack DG, Parraga G. Semi-automated segmentation of pulmonary ventilation using hyperpolarized ${ }^{3} \mathrm{He}$ magnetic resonance imaging. In: Biomedical Engineering Society Annual Meeting 2010, Imaging the Lung-The New Frontier, 82: 2010.

13. Heydarian M, Kirby M, Wheatley A, Fenster A, Parraga G. Two and three-dimensional segmentation of hyperpolarized $3 \mathrm{He}$ magnetic resonance functional imaging. In: Proceedings of SPIE, The Biomedical Applications in Molecular, Structural, and Functional Imaging, edited by Molthen RC and Weaver JB, 8317: 2011

14. Hogg JC, Chu F, Utokaparch S, Woods R, Elliott WM, Buzatu L, Cherniack RM, Rogers RM, Sciurba FC, Coxson HO, Pare PD. The nature of small-airway obstruction in chronic obstructive pulmonary disease. N Engl J Med 350: 2645-2653, 2004.

15. James AL, Wenzel S. Clinical relevance of airway remodelling in airway diseases. Eur Respir J 30: 134-155, 2007.

16. Jones PW. Health status measurement in chronic obstructive pulmonary disease. Thorax 56: 880-887, 2001.

17. Kauczor HU, Ebert M, Kreitner KF, Nilgens H, Surkau R, Heil W, Hofmann D, Otten EW, Thelen M. Imaging of the lungs using 3He MRI: preliminary clinical experience in 18 patients with and without lung disease. J Magn Reson Imaging 7: 538-543, 1997.

18. Kirby M, Mathew L, Heydarian M, Etemad-Rezai R, McCormack DG, Parraga G. Chronic obstructive pulmonary disease: quantification of bronchodilator effects by using hyperpolarized He MR imaging. Radiology 261: 283-292, 2011.

19. Kirby M, Mathew L, Wheatley A, Santyr GE, McCormack DG, Parraga G. Chronic obstructive pulmonary disease: longitudinal hyperpolarized (3)He MR imaging. Radiology 256: 280-289, 2010.

20. Kirby M, Svenningsen S, Ahmed H, Wheatley A, Etemad-Rezai R, Paterson NA, Parraga G. Quantitative evaluation of hyperpolarized helium-3 magnetic resonance imaging of lung function variability in cystic fibrosis. Acad Radiol 18: 1006-1013, 2011.

21. MacQueen, J. Some methods for classification and analysis of multivariate observations. In: Proceedings of the Fifth Berkeley Symposium on Mathematical Statistics and Probability 1 (Statistics), edited by Le Cam LM and Neyman J. Berkeley, CA: University of California Press, 1967, p. 281-297.

22. Mathew L, Evans A, Ouriadov A, Etemad-Rezai R, Fogel R, Santyr G, McCormack DG, Parraga G. Hyperpolarized 3He magnetic resonance imaging of chronic obstructive pulmonary disease: reproducibility at 3.0 tesla. Acad Radiol 15: 1298-1311, 2008.

23. Mathew L, Kirby M, Etemad-Rezai R, Wheatley A, McCormack DG, Parraga G. Hyperpolarized $3 \mathrm{He}$ magnetic resonance imaging: preliminary evaluation of phenotyping potential in chronic obstructive pulmonary disease. Eur J Radiol 79: 140-146, 2011.

24. Matsuba K, Thurlbeck WM. The number and dimensions of small airways in nonemphysematous lungs. Am Rev Respir Dis 104: 516-524, 1971

25. Moller HE, Chen XJ, Saam B, Hagspiel KD, Johnson GA, Altes TA, de Lange EE, Kauczor HU. MRI of the lungs using hyperpolarized noble gases. Magn Reson Med 47: 1029-1051, 2002.
26. Morbach AE, Gast KK, Schmiedeskamp J, Dahmen A, Herweling A, Heussel CP, Kauczor HU, Schreiber WG. Diffusion-weighted MRI of the lung with hyperpolarized helium-3: a study of reproducibility. J Magn Reson Imaging 21: 765-774, 2005.

27. Morrell NW, Wignall BK, Biggs T, Seed WA. Collateral ventilation and gas exchange in emphysema. Am J Respir Crit Care Med 150: 635-641, 1994.

28. O'Donnell DE, Aaron S, Bourbeau J, Hernandez P, Marciniuk DD, Balter M, Ford G, Gervais A, Goldstein R, Hodder R, Kaplan A, Keenan S, Lacasse Y, Maltais F, Road J, Rocker G, Sin D, Sinuff T, Voduc N. Canadian Thoracic Society recommendations for management of chronic obstructive pulmonary disease-2007 update. Can Respir J 14, Suppl B: 5B-32B, 2007.

29. O'Donnell DE, Forkert L, Webb KA. Evaluation of bronchodilator responses in patients with "irreversible" emphysema. Eur Respir J 18: 914-920, 2001.

30. O'Donnell DE, Lam M, Webb KA. Measurement of symptoms, lung hyperinflation, and endurance during exercise in chronic obstructive pulmonary disease. Am J Respir Crit Care Med 158: 1557-1565, 1998.

31. O'Halloran RL, Holmes JH, Altes TA, Salerno M, Fain SB. The effects of SNR on ADC measurements in diffusion-weighted hyperpolarized He-3 MRI. J Magn Reson 185: 42-49, 2007.

32. Ochs M, Nyengaard JR, Jung A, Knudsen L, Voigt M, Wahlers T, Richter J, Gundersen HJ. The number of alveoli in the human lung. Am J Respir Crit Care Med 169: 120-124, 2004.

33. Parraga G, Ouriadov A, Evans A, McKay S, Lam WW, Fenster A, Etemad-Rezai R, McCormack D, Santyr G. Hyperpolarized $3 \mathrm{He}$ ventilation defects and apparent diffusion coefficients in chronic obstructive pulmonary disease: preliminary results at 3.0 Tesla. Invest Radiol 42 : 384-391, 2007.

34. Pauwels RA, Buist AS, Calverley PM, Jenkins CR, Hurd SS, GOLD Scientific Committee. Global strategy for the diagnosis, management, and prevention of chronic obstructive pulmonary disease. NHLBI/WHO Global Initiative for Chronic Obstructive Lung Disease (GOLD): Workshop summary. Am J Respir Crit Care Med 163: 1256-1276, 2001.

35. Pauwels RA, Rabe KF. Burden and clinical features of chronic obstructive pulmonary disease (COPD). Lancet 364: 613-620, 2004.

36. Petty TL, Silvers GW, Stanford RE. Radial traction and small airways disease in excised human lungs. Am Rev Respir Dis 133: 132-135, 1986.

37. Rabe KF, Hurd S, Anzueto A, Barnes PJ, Buist SA, Calverley P, Fukuchi Y, Jenkins C, Rodriguez-Roisin R, van Weel C, Zielinski J. Global strategy for the diagnosis, management, and prevention of chronic obstructive pulmonary disease: GOLD executive summary. Am J Respir Crit Care Med 176: 532-555, 2007.

38. Saam BT, Yablonskiy DA, Kodibagkar VD, Leawoods JC, Gierada DS, Cooper JD, Lefrak SS, Conradi MS. MR imaging of diffusion of (3)He gas in healthy and diseased lungs. Magn Reson Med 44: 174-179, 2000.

39. Salerno M, de Lange EE, Altes TA, Truwit JD, Brookeman JR, Mugler JP, III. Emphysema: hyperpolarized helium 3 diffusion MR imaging of the lungs compared with spirometric indexes-initial experience. Radiology 222: 252-260, 2002.

40. Walter SD, Eliasziw M, Donner A. Sample size and optimal designs for reliability studies. Stat Med 17: 101-110, 1998.

41. Woods JC, Choong CK, Yablonskiy DA, Bentley J, Wong J, Pierce JA, Cooper JD, Macklem PT, Conradi MS, Hogg JC. Hyperpolarized $3 \mathrm{He}$ diffusion MRI and histology in pulmonary emphysema. Magn Reson Med 56: 1293-1300, 2006.

42. Woods JC, Yablonskiy DA, Choong CK, Chino K, Pierce JA, Hogg JC, Bentley J, Cooper JD, Conradi MS, Macklem PT. Long-range diffusion of hyperpolarized $3 \mathrm{He}$ in explanted normal and emphysematous human lungs via magnetization tagging. J Appl Physiol 99: 1992-1997, 2005.

43. Yablonskiy DA, Sukstanskii AL, Leawoods JC, Gierada DS, Bretthorst GL, Lefrak SS, Cooper JD, Conradi MS. Quantitative in vivo assessment of lung microstructure at the alveolar level with hyperpolarized 3He diffusion MRI. Proc Natl Acad Sci USA 99: 3111-3116, 2002.

44. Yablonskiy DA, Sukstanskii AL, Woods JC, Gierada DS, Quirk JD, Hogg JC, Cooper JD, Conradi MS. Quantification of lung microstructure with hyperpolarized 3He diffusion MRI. J Appl Physiol 107: 1258$1265,2009$. 